\title{
LOCUS OF CONTROL IN RELATION TO FLOW
}

\author{
CELESTE MARIÉ TAYLOR \\ JM SCHEPERS \\ F CROUS \\ fc@rau.ac.za \\ Programme in Industrial Psychology \\ Department of Human Resource Management \\ University of Johannesburg
}

\begin{abstract}
The principal objective of the study was to examine the relationship between locus of control and optimal experience (flow) in carrying out work and/or study activities. Two questionnaires measuring the aforementioned constructs were administered to a group of first and second-year Human Resource Management students ( $n=168$ ) between the ages of 16 and 30. The results suggest that more frequent experience of flow is positively correlated with Autonomy and Internal Locus of Control. Limitations, lines of future research, implications and further contributions are discussed.
\end{abstract}

Key words

Flow, locus of control, attribution theory, autonomy, Internet control

The complex path to the actualisation of human potential, as defined by Abraham Maslow (1968 and 1970) has for long been the focus of much attention and elaboration in social science research (Maslow, 1968, 1970; McClelland, 1965; Alderfer, 1972; Csikszentmihalyi, 1992, 1996, 1997 and 2000; Mirvis, 1996; Harung, 1998; Butts, 1999; Shelton \& Darling, 2001). As the world of work becomes increasingly focused on tapping into the optimal potential capacity of the individual in order to produce the best performance results (Harung, 1997; Neck, Smith \& Godwin, 1997; Emiliani, 1998a, Emiliani, 1998b; Sashittal \& Jassawalla, 1998) it is observed that some individuals have the tendency to continually direct themselves to heightened levels of performance standards and personal growth, while others remain passive in their response to potentially enriching experiences.

Why do individuals, who perceive a link between situational outcomes and own behaviour, appear to perform consistently better in work and/or studies? A part-answer to this question lies in the theory of locus of control. Locus of control (LOC), from an attribution theory perspective, builds on Rotter's (1966) original social learning-based conceptualisation (Weiner \& Graham, 1999). An internal locus of control is based on the personal perception that reinforcements are attributed to personal factors and can be influenced by adjusting one's own behaviour (e.g. increasing level of effort, upskilling etc). An external locus of control is based on the personal perception that reinforcements are attributed to external factors and are therefore not within the limits of personal control (e.g. luck, fate, circumstances, etc.) (Pettersen, 1987).

Whilst being grounded in social learning theory, LOC lends itself to relevance in attribution theory because it is clearly linked to the locus dimension of causality (Jaspars, Fincham \& Hewstome, 1983; Försterling, 1988; Weiner \& Graham, 1999). Based on this foundational attribution theory-based conceptualisation of LOC, the broad question is posed, "To what can X-outcome (e.g. success/health/mental wellbeing) be attributed?" As attribution theory is concerned with causal inferences or the perceived reason(s) an event has occurred, the basic theory of LOC provides insight into the link between perceived personal control over events and the nature of causal inferences. Although LOC has often been incorrectly interpreted as a fixed, innate personality trait, it has been confirmed through the existing body of research that individual tendencies can vary depending on the situational context (Lopez \& Snyder, 2003). As such, this study focuses on LOC trends in behaviour, with specific reference to perceived causal inferences contributing to success in study and/or work life.
With specific reference to perceived reasons for success in work and study life, the literature lends itself to suggest that there are a number of intrinsic benefits linked to having a more internal LOC while, conversely, a number of performance-inhibiting factors have been associated with a more external orientation. To expand on this observation, a more internally oriented individual might display higher levels of future time orientation and academic goal setting (Leith, 1996; Lesane \& Jones, 1999; Wolf \& Savickas in Wolf \& Bandura, 1989). Internals from selected sampled populations have also been shown to be more likely to display higher levels of self-regulation in setting shortterm goals (Wolf \& Bandura, 1989). Other positive intrinsic benefits might include better academic performance (Czubaj, 1996; Kalechstein \& Nowicki, 1997; Smith, Sapp, Farrel \& Johnson, 1998); increased frequencies of achievement-oriented daydreaming (Brannigan \& Hawk, 1991); greater life satisfaction (Hong \& Giannakopulos, 1994); higher levels of academic selfesteem (Smith, Sapp, Farrel \& Johnson, 1998 and Herbert, 1998); and more openness to change under the perception of probable successful outcomes (Lau and Woodman, 1995).

Conversely, in considering research conducted with individuals who have a more external orientation, specifically students and graduates, such individuals have been known to lend themselves to higher frequencies of procrastination in carrying out work assignments (Jansen \& Carton, 1999) as well as experiencing their work environment as being more threatening or stressful than do fellow students who have a more internal locus of control (Spector \& O'Connel, 1994). Other performanceinhibiting constructs that have been linked to those with a stronger external orientation (as opposed to internal orientation) include higher levels of performance anxiety (Johnson, Kennedy \& Porter, 2001; Fink, Johnson, Kennedy \& Porter, 2001) and lower levels of task planning behaviour (Das, Naglieri \& Murphy, 1995).

Considering the behavioural tendencies identified in previous studies that focused on the characteristics of internals and externals, it would make sense that internally oriented individuals are better able to reach higher levels of performance within a shorter space of time, in turn being better able to accelerate the fulfilment of the high-order need for selfactualisation

Another key to understanding the nature of optimal experience lies in the concept of flow, as a state of optimal experience. Researched and coined by Mihali Csikszentmihalyi (1990, 1992, 1996, and 1997; O'Shaughnessy, 1997) flow, similar to what Maslow (1968) termed peak experiences and Rosch (in Scharmer 2001) termed primary knowing, is said to be a state of optimal 
experience that individuals describe when performing at their best (within the boundaries of their ability at any given time). The word 'flow' is a metaphor used to describe those moments that stand out as being the best of a person's life (Csikszentmihalyi, 1997; Harung, 2001). The concept of flow holds significance when the path to self-actualisation is considered. According to Csikszentmihalyi (2000) an individual may experience joy or serenity if external conditions are satisfactory or perceived as being nice. However, if conditions of autonomy, creativity and optimism cannot be created regardless of environmental factors, the individual will still remain trapped in the lower stages of personal development.

Extensive research has indicated that there are specific characteristics associated with being in a state of flow. These (mental states) characteristics are likened to the physical state reported by athletes when they enter what is known as 'the zone' (Sears \& Lawren, 1995). Although many researchers use the terms interchangeably, flow might differ from the physical state of being in the zone, as an individual can enter a state of flow at various levels of performance (within the boundaries of his or her abilities at any given time) while the zone is only entered when an individual is performing at the highest level possible and for longer periods of time (Hanin, 2000). Also, the flow state has been described as being a mental process while being in the zone has been linked more clearly to a set of physiological (hormonal) characteristics (Sears \& Lawren, 1995). In order for a person to enter a state of flow, there should first, be a balance between the challenge that is demanded from a given task and the level of skill that the person requires in meeting that challenge (Csikszentmihalyi, 1997). Consider the example of a student completing a series of academic assignments. Should the level of skill that the student possesses exceed the level of challenge offered through any of the assignments, the student will experience boredom, which subsequently limits experiences of positive affect (Daniels, 2000). Conversely, should the challenge exceed the level of skill posessed by the student, anxiety is likely to be a behavioural outcome. Anxiety also increases the probability for experiences of negative affect (Daniels, 2000).

The following diagram illustrates the relationship between levels of challenge and skill in reaching the ideal flow state.

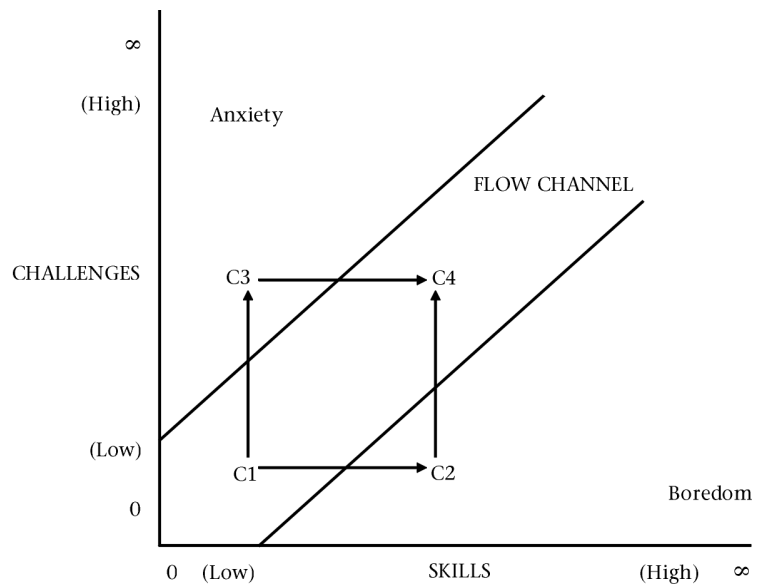

Figure 1: Challenge versus level of task complexity (Adapted from Csikszentmihalyi, 1992)

In Figure 1 challenge and skill are presented on each of the axes (X and Y). If Figure 1 is applied to the practical example of a student completing academic assignments, then the letter $\mathrm{A}$ is interpreted as the variation of combinations of levels of challenge and skill at various stages of task engagement. By engaging in the task of completing a basic assignment the student requires limited skill and the level of the challenge faced is also low because the task is perceived by the student as being elementary (A1). At this point the student is enjoying the assignment because the level of difficulty meets the skill that he or she possesses. As the student progresses through and beyond elementary level assignments, the level of skill increases, yet the challenge remains the same (A2). The student then experiences boredom. Should the student be exposed to a higher level of academic challenge at that point, the challenge required will be higher than the level of skill available to carry out the task. At that point the student will experience anxiety (A3). The assignment has now become too difficult for the student. If the student works at increasing the level of skill required in order to meet the new challenge, the result is greater enjoyment and flow experience (A4).

Although Csikszentmihalyi (1996) claims that new skills and opportunities are sought once people become bored and frustrated, several authors (including Torbert, 1991; Shelton \& Darling, 2001; and Scharmer, 2001) comment that very few people ever reach the full self-actualised state in their lives (approximately one percent). Although the opportunities for growth appear naturally as tasks are mastered, not all people decide (be it consciously or unconsciously) to take up the challenge of increasing their level of skill. It is for this reason that personal variables (such as LOC) should be considered where mechanisms for reaching self-actualisation (e.g. flow) are concerned.

In addition to the requirement of a balance between level of skill and challenge, a second characteristic of the flow state is that it results in the acknowledgement that the individual has experienced enjoyment of the task, following its completion (Csikszentmihalyi, 1992). In order to clarify what is meant by the term 'enjoyment', the related concept of 'pleasure' must be elaborated on first. Pleasure can be defined as the feeling of contentment that is achieved whenever information in consciousness indicates that expectations set by biological programmes or social conditioning have been met (Cohen, 1991; Csikszentmihalyi, 1992). Some examples might be watching a movie, eating good food or travelling to exotic places (Csikszentmihalyi, 1997, 2000). Pleasure is said to be an important part of quality of life but, in itself, cannot bring happiness. Engaging in a pleasurable experience does not lead to self-actualisation because an immediate (often superficial level) need is met without full mental and/or physical engagement.

The state of enjoyment (as opposed to pleasure) that is brought about when a person enters a state of flow implies that proactive charge must be taken by the individual to engage mentally in the completion of a challenging task (Csikszentmihalyi, 1997). This task engagement results in a feeling of enjoyment only once the task has been completed and the individual has made a concerted, conscious effort to limit psychic entropy (Csikszentmihalyi, 1992). After the flow experience has been completed, longer-term happiness is therefore more secure as a result of the successful investment of psychic energy (negentropy) in a specific goal that has been decided and pursued by the individual (Csikszentmihalyi, 1992).

A third characteristic of the flow state involves the task being described by the individual as autotelic. An autotelic experience means that the task is worthwhile engaging in for its own sake. In order to experience flow, adequate intrinsic motivation is required. This intrinsic motivation results in a controlled and conscious focus on the goal at hand rather than on extrinsic rewards (Csikszentmihalyi, 1997). Designing tasks to be more intrinsically rewarding, according to Csikszentmihalyi (1999), means that those engaged in the task are on their way to a lifetime of self-propelled acquisition of knowledge and personal growth. Whilst a personality construct has been identified, - the autotelic personality (Csikszentmihalyi, 2002), which describes the type of person who experiences tasks as being autotelic and 
enjoyable (Emiliani, 1998a) - very few other better-known and researched personality variables relating to the flow state have been investigated.

When someone is in a state of flow, he/she experiences a strong sense of personal control over the mastery of the task (Csikszentmihalyi, 1992). This mastery provides the foundation for the development of self-esteem. Self-esteem development occurs because the person is performing at his or her best and achieving clear goals with immediate feedback, as specified through the task. The immediate feedback that is available following the flow state provides insight into the developmental needs and competency levels of the individual (Saunders, 2000).

Lastly, a characteristic experience when an individual enters a state of flow is that all sense of time is distorted. Hours seem to pass in minutes. An individual could glance at a watch and notice that three hours have passed, when the task engagement experience merely seemed as though it had taken place for half an hour.

Research conducted by Csikszentmihalyi (1992, 1995, 1997) indicates that there are a number of measurable effects of the flow experience. These include, amongst others:

1. Creativity

2. Talent development

3. Productivity

4. Stress reduction

5. Improved self-esteem.

The existing body of research pertaining to the flow construct has been carried out predominantly in the areas of computer end-user behaviour and education. The major shortcoming of much of this research is that personal variables are not considered as a factor impacting on the frequency and nature of flow experiences (Varley \& Crowther, 1998). Studies have focused on identifying and unpacking the activities engaged in by the subjects rather than on the personal factors specific to those individuals. For example, much of the research focusing on flow in the area of human-computer interface and online consumer behaviour (Novak \& Hoffman, 1997a, 1997b, 2001; Steyn, 1999; Goulding, 2000; Chen, Wigand \& Nilan, 2000; Rettie, 2001; Hefner, 2002; Smith \& Sivakumar, 2002) has focused on the nature, design and utilisation of technology, the end-user experience, as well as the structuring of the relevant end-user activity. Relating to online consumer behaviour, for example, it has been found that consumers do experience flow while interacting with computers and using the Web (Internet) (Novak, 1997, 2001; Steyn, 1999; Novak, Hoffman \& Duhachek, 2001; Chen, Wigand \& Nilan, 2000). Some studies have taken research in this area to the next level, in considering the experiencing of positive emotions (e.g. arousal and selfconfidence) when experiencing flow during online computer experiences. However, once again the effect of personal variables has not been considered (Quinn, 2003).

Rock climbing is another activity said to be more flow-inducing (Varley \& Crowther, 1998). In maintaining the suggested stance that flow relates more specifically to mentally challenging activities versus being in the zone (more physical activities) these would be considered to be more zone-oriented than floworiented activities. The playing of self-selected, asynchronous background music has also been shown to increase experiences of flow (Pates, Karageorghis, Fryer \& Maynard, 2001) as well as subsequently improving netball players' goal-shooting performance. This research suggests (though not overtly) a possible link between flow and zone experiences. There is insufficient research to corroborate the existence of such a link at this time.

The task-focused trend in flow-related research follows suit in the education arena. For example, in linking flow to the process of lifelong learning, it has been suggested that the theory behind the flow construct be considered during the design and development of learning interventions (Steyn, 1999). However, once again studies such as this focus more on the design of the activity than the personal factors differentiating between types of individuals.

However limiting, a degree of overlap has been established between the characteristic behaviours of someone who has a high internal LOC and someone who experiences flow more frequently. Flow has also been related to a number of intrinsically valuable variables. Higher incidences of flow experience have been linked to future-oriented goal setting (Novak, Hoffman \& Duhachek, 2001). In addition higher incidences of flow have also been linked to world-class performers versus average performers in organisations (Harung, 2001).

Considering the limited number of studies linking LOC with flow, Csikszentmihalyi (1990) believes that the generation of an individual's intentions involves a psychological process that results in a construction of the person's unique reality. If individuals are required to consciously understand their intentions in order to align subjective perceptions with personal desires (Shelton \& Darling, 2001), it makes sense that LOC would be a factor contributing to the outcome of this process. A similar link is suggested by Diamanté and London (2001) where the construct of expansive leadership is said to include a tendency toward self-regulation, desire for continuous learning and self-efficacy. The long-term results of expansive leadership have been said to include peak experiences (as described by Csikszentmihalyi and Sheldon, Elliot, Kim, Kasser, 2001). Selective elements of the concept of expansiveness bear close similarity with the elements of having a more internal LOC (selfregulation, desire for continuous learning and self-efficacy). Based on the premise outlined by Shelton and Darling, 2001, it makes sense that an individual who tends toward a more external orientation would unconsciously generate self-talk to reinforce subjective beliefs and perceptions. These beliefs and perceptions would subsequently guide the behavioural responses of that individual (e.g. passive reactive behaviour), thereby limiting the likelihood of proactive and self-directed action toward taking up new and more complex challenges.

Based on the presentation of the literature, the overall hypothesis is that an internal locus of control is associated with high levels of flow experience and autonomy.

Some extraneous variables have been highlighted in the literature that could impact on the results of this study. Klein and Wasserstein-Warnet (2000) concluded that internally oriented individuals might resort to tendencies associated with a more external locus of control to cope in cases where personal control over the immediate environment is limited. Since the personal circumstances surrounding each respondent are unknown, some students might have resorted to a more external locus of control to cope with personal stress. Similarly in Yousef (2000) the Islamic work ethic was found to be a mediating factor between locus of control, role conflict and role ambiguity. Although full-time university students (as the target sample of this study) typically have a high degree of personal freedom in influencing their immediate environments, it cannot be assumed that all subjects have a high degree of control over their personal environments. The impact of parental and other controlling agents cannot be eliminated.

Another possible extraneous variable relates to the year of study of the target sample group. Students in their first or second year at university do not always have a mature awareness of where their strengths lie in terms of the content focus of their courses (Kimweli, 1999). Only as they mature in career and self-awareness do they tend to appreciate their specialisation subjects more. 
A final consideration relates to the area of an individual's expertise and preferences. A mismatch between field of study and individual preference may limit the likelihood of flow experiences. This is a common occurrence within the first and even second year of study at university where the field of study may, in some cases, be determined by parental influences, high school results or the course selection of peers.

\section{Statement of problem}

The principal objective of the study was to determine the relationship between locus of control and optimal experience (flow) in carrying out work and/or study activities. To investigate this problem, the following hypotheses were formulated:

H1: There is a statistically significant positive relationship between internal control and flow.

$\mathrm{H} 2$ : There is a statistically significant positive relationship between autonomy and flow.

H3: There is a statistically significant positive relationship between internal control and autonomy.

H4: There is a statistically significant canonical correlation between the measures of locus of control and the measures of flow.

\section{RESEARCH DESIGN}

\section{Research approach}

A correlational approach was followed in the analysis of the data, which were collected by means of a cross-sectional field survey.

\section{Participants}

The sample for this study consisted of 168 Human Resource Management students from three Higher Education Institutions in South Africa. A sample of convenience was used in this study. The sample is described as follows:

Human Resource Management Diploma students constituted $71.4 \%$ of the sample whilst the other $28 \%$ were Human Resource Management Degree students. The percentage of students who did not indicate their current qualification was $0.6 \%$.

The respondents ranged from 17 to 30 years of age with a mean and median age of 21 .

TABLE 1

DesCRIPTIVE STATISTICS: AgE

\begin{tabular}{cccccc}
\hline & Age & Frequency & Percent & Valid Percent & $\begin{array}{c}\text { Cumulative } \\
\text { Percent }\end{array}$ \\
\hline Valid & 17 & 1 & 0,6 & 0,8 & 0,8 \\
& 18 & 12 & 7,1 & 9,1 & 9,8 \\
& 19 & 22 & 13,1 & 16,7 & 26,5 \\
& 20 & 26 & 15,5 & 19,7 & 46,2 \\
& 21 & 28 & 16,7 & 21,2 & 67,4 \\
& 22 & 15 & 8,9 & 11,4 & 78,8 \\
& 23 & 13 & 7,7 & 9,8 & 88,6 \\
& 24 & 6 & 3,6 & 4,5 & 93,2 \\
& 25 & 5 & 3,0 & 3,8 & 97,0 \\
& 27 & 3 & 1,8 & 2,3 & 99,2 \\
& 30 & 1 & 0,6 & 0,8 & 100,0 \\
& Total & 132 & 78,6 & 100,0 & - \\
Missing & Missing & 36 & 21,4 & - & - \\
& Cases & & & & - \\
\hline
\end{tabular}

The first language of respondents varied greatly. However, more than half of those who responded to the questionnaires, spoke Sotho as a first language (53\%). The remaining $47 \%$ spoke either
English, Afrikaans, Zulu, Xhosa, Venda, Swazi, Ndebele or another undisclosed language as a first language.

TABLe 2

Descriptive STATISTICS: First language

\begin{tabular}{cccccc}
\hline & Language & Frequency & Percent & Valid Percent & $\begin{array}{c}\text { Cumulative } \\
\text { Percent }\end{array}$ \\
\hline Valid & English & 1 & 0,6 & 0,8 & 0,8 \\
& Afrikaans & 12 & 7,1 & 9,1 & 9,8 \\
Zulu & 22 & 13,1 & 16,7 & 26,5 \\
Xhosa & 26 & 15,5 & 19,7 & 46,2 \\
Sotho & 28 & 16,7 & 21,2 & 67,4 \\
Venda & 15 & 8,9 & 11,4 & 78,8 \\
Swazi & 13 & 7,7 & 9,8 & 88,6 \\
& Ndebele & 6 & 3,6 & 4,5 & 93,2 \\
Other & 5 & 3,0 & 3,8 & 97,0 \\
Total & 162 & 96,4 & 100,0 & - \\
Missing & Missing & 6 & 3,6 & - & - \\
Cases & & & & - \\
\hline
\end{tabular}

There were significantly more female respondents than males. This is attributed to the number of females who are currently registered for Human Resource Management qualifications.

With reference to cultural groupings the majority of respondents were Black 79,2\%; 16,1\% were White; $2,4 \%$ Coloured and $1,8 \%$ Asian. Only $0,6 \%$ of the respondents did not give any indication of the cultural group to which they belong. The reason for $79,2 \%$ of respondents being Black is that the majority of cases were sourced from an institution where there are significantly more Black students than there are representatives from any of the other population groups.

\section{Measuring Instruments}

In the execution of the study two existing inventories were used, namely the Locus of Control Inventory (LCI) of Schepers, 1994 (revised in 1999) and the Flow Experience Survey (FES) first developed by Andersen, Crous, and Schepers (1996) and revised by Percival, Crous and Schepers in 2001.

The revised Locus of Control Inventory consists of 88 items. Based on attribution theory these items concern the perceived factors and circumstances that influence behaviour with regard to general success in study and/or work life. Three factors have consistently emerged from the LCI, namely Internal Control, Autonomy and External Control. In a joint analysis of LCI, Emotional Quotient Inventory, the Personal Orientation Index and the Sense of Coherence inventory three common factors were obtained and interpreted as Psychological Adjustment, Self- Actualisation and Stress Management $(n=2091)$. Persons with high scores on Internal Control and Autonomy are convinced that success in life depends on their own abilities and dedication. They are convinced that they are able to overcome adverse circumstances and solve complex problems on their own (Schepers, 2006). Furthermore such individuals have been shown to be cheerful, positive, hopeful and optimistic. This measuring instrument has been administered to a number of South African student groups of varying ages and races. It has been proven to be a culturally fair measurement tool within the diverse South African context.

The readability of the Locus of Control Inventory is rated at 11 on Robert Gunning's FOG Index. This indicates that the inventory is suited for mother-tongue users of English at Std 9 (Grade 11) level and above. The instrument is deemed applicable considering that the sample group for this study is made up of first and second-year tertiary education students at institutions where courses are presented in English. 
The FES has gone through several revisions. The latest revision was done by Percival et al. (2001) ( $\mathrm{n}=307)$ where the original number of items was extended to 69 . The results were subjected to a factor analysis. From the factor analysis two factors emerged, namely Enjoyment and Control of Consciousness. This instrument was applied to the current sample of 168 cases and the reliabilities were re-estimated.

For the purposes of this study the FES was translated into Afrikaans, back translated and professionally edited. It was initially deemed necessary to make the survey available in both the lecture media languages of the target institutions. However, additional institutions were utilised in order to increase the sample size. This resulted in the majority of the sample being Sotho-speaking. The item format is a Likert-type format in the form of statements, positively or negatively directed. The response format is that of agreeing or disagreeing on a five-point scale.

Once the surveys had been administered, the statistical analyses were done to determine whether the instruments were appropriate and reliable. Although the validity of each instrument could not be confirmed in this study on account of a sample size that was too small for this purpose, the background of each inventory suggests that they are valid measures of the factors presented.

\section{Procedure}

The data were collected during student's classtime. Care was taken to ensure that there were no disruptions during the session when the instruments were administered. All administration sessions were supervised by a researcher, who was also available to respond to questions. No time limit was imposed. Most subjects took approximately 45-60 minutes to complete both inventories. Question and answer sheets were collected from the students before they left the room.

\section{Analysis of the data}

Cases characterised by more than five missing values were excluded from the study, reducing the number of usable cases from 212 to 168 . Missing values in the remaining 168 cases were estimated by using the regression algorithms in Microsoft's SPSS programme. There were no patterns in the missing values.

In the analysis of the data use was made of product-moment correlations and canonical correlation analysis. As the latter technique is not generally known it will briefly be clarified here:

A canonical correlation represents the correlation between two composites, coming from two batteries of tests. One linear combination of variables is formed from each of the batteries. The linear combinations are formed in such a way that the correlation between the two composites is a maximum. Such a linear combination of variables is known as a canonical variate. Normally we refer to the two sets of variables (canonical variates) as the $\mathrm{X}$-variate and the $\mathrm{Y}$-variate. The canonical correlation is then the correlation between the $\mathrm{X}$-variate and the Y-variate. Further linear combinations can be formed such that the correlation between the $\mathrm{X}$ and $\mathrm{Y}$ components are a maximum (Hair, Anderson, Tatham \& Black, 1995). Canonical loadings can be calculated by correlating the original measures of both batteries with the respective canonical variates. These loadings can be interpreted like factor loadings.

As far as research design is concerned it is recommended that there be at least ten observations for each variable (Hair et al., 1995). In the present case there are five variables and 168 observations.
The following statistical assumptions are made:

1. Multivariate normality of the measures is required by the statistical test of significance of the canonical correlations

2. The mutual correlations between the variables must be linear

3. The canonical correlations, as such, must also be linear (Hair et al., 1995)

\section{RESULTS}

As a first step in the analysis of the data the reliabilities of the two measuring instruments used were estimated for the present sample. Cronbach alpha coefficients of 0,822, 0,862 and 0.876 were obtained for Autonomy, External Control and Internal Control respectively. The two scales of the FES yielded Cronbach alpha coefficients of 0,912 and 0,801 for Enjoyment and Control of Consciousness respectively. Thus all the measures of both instruments are of acceptable reliability.

In order to test Hypotheses 1, 2 and 3 the various measures of the LCI and FES were intercorrelated. The results are given in Table 3.

TABLE 3

INTERCORRELATION MATRIX

\begin{tabular}{|c|c|c|c|c|c|}
\hline & $\begin{array}{c}\text { LCI - } \\
\text { Autonomy }\end{array}$ & $\begin{array}{c}\text { LCI - } \\
\text { External } \\
\text { Control }\end{array}$ & $\begin{array}{c}\text { LCI - } \\
\text { Internal } \\
\text { Control }\end{array}$ & $\begin{array}{c}\text { FES - } \\
\text { Enjoyment }\end{array}$ & $\begin{array}{c}\text { FES - } \\
\text { Control of } \\
\text { Conscious- } \\
\text { ness }\end{array}$ \\
\hline $\begin{array}{l}\text { LCI - } \\
\text { Autonomy }\end{array}$ & ny & $-0,109$ & $0,681(* *)$ & $0,624(* *)$ & $0,350(* *)$ \\
\hline $\begin{array}{l}\text { LCI - } \\
\text { External } \\
\text { Control }\end{array}$ & $-0,109$ & 1 & $-0,100$ & $-0,072$ & 0,068 \\
\hline $\begin{array}{l}\text { LCI - } \\
\text { Internal } \\
\text { Control }\end{array}$ & $0,681(* *)$ & $-0,100$ & 1 & $0,550(* *)$ & $0,371(* *)$ \\
\hline $\begin{array}{l}\text { FES - } \\
\text { Enjoymen }\end{array}$ & $0,624(* *)$ & $-0,072$ & $0,550(* *)$ & 1 & $0,531(* *)$ \\
\hline $\begin{array}{l}\text { FES - } \\
\text { Control } \\
\text { of Con- } \\
\text { sciousness }\end{array}$ & $\begin{array}{l}0,350(* *) \\
\text { ss }\end{array}$ & 0,068 & $0,371(* *)$ & $0,531(* *)$ & 1 \\
\hline
\end{tabular}

Note. ${ }^{* *}$ Correlation is significant at the 0,01 level (2-tailed).

Listwise $\mathrm{n}=168$

From an inspection of Table 3 it appears that Autonomy is highly correlated with Enjoyment $(r=0,624 ; p=0,01)$ and moderately with Control of Consciousness $(r=0,350 ; p=0,01)$. Similarly Internal Control is highly correlated with Enjoyment $(\mathrm{r}=0,550$; $\mathrm{p}=0,01)$ and moderately with Control of Conscious $(\mathrm{r}=0,371 ; \mathrm{p}$ $=0,01)$. External Control is uncorrelated with the two measures of the FES. The FES measures correlated $0,531(p=0,01)$ with one another. Autonomy and Internal control correlated 0,681 ( $\mathrm{p}=$ $0,01)$ with each other. Both measures are uncorrelated with External Control.

From the foregoing it is clear that there is strong support for Hypotheses 1, 2 and 3.

To test Hypothesis 4, it was decided to compute the canonical correlation(s) between the measures of locus of control on the one hand and the flow measures on the other.

As a first step in the analysis, Bartlett's (1951) test of significance was performed to determine the number of statistically significant canonical correlations. Bartlett's test is shown in Table 4. 
TABLE 4

STATISTICAL SIGNIFICANCE OF CANONICAL CORRELATIONS BARTLETT'S TEST IN RESPECT OF THE LCI AND FES

\begin{tabular}{cccccccc}
\hline Eigenvalues & $\begin{array}{c}\text { Canonical } \\
\text { correlations }\end{array}$ & $\begin{array}{c}\text { Eigenvalue } \\
\text { removed }\end{array}$ & \multicolumn{4}{c}{$\begin{array}{c}\text { Significance of } \\
\text { remaining eigenvalues }\end{array}$} \\
\hline & & & $\chi^{2}$ & df & p & $\begin{array}{c}\text { Lambda } \\
\text { prime }\end{array}$ \\
\hline 0,420747 & 0,648650 & 0 & 93.98293 & 6 & $<0,00000$ & 0,563794 \\
0,026688 & 0,163365 & 1 & 4.43634 & 2 & 0,108825 & 0,973312 \\
\hline
\end{tabular}

Note. $n=168$

From an inspection of Table 4 it is clear that the first canonical correlation is 0,649 and the second is 0,163 . However, only the first canonical correlation is statistically significant, the chi square value associated with it being 93,983, which is statistically highly significant $(\mathrm{p}<0.00001)$. The second canonical correlation of 0,163 is statistically not significant. Accordingly the canonical correlation analysis was done, and is given in Table 5 .

TABLE 5

Canonical CORRelations OF LCI (IVS) WITH THE RESPECTIVE MEASURES OF THE FES (DVs)

\begin{tabular}{lccc}
\hline Variables & Variate 1 & Variate 2 & \\
\hline LCI: Autonomy & $+0,961$ & $-0,179$ & \\
LCI: External Control & $-0,94$ & 0,802 & \\
LCI: Internal Control & $+0,857$ & 0,290 & \\
Average \% variance accounted for & $55,54 \%$ & $25,30 \%$ & Total: $80,84 \%$ \\
Average \% redundancy & $23,37 \%$ & $0,68 \%$ & Total: $24,04 \%$ \\
FES: Enjoyment & $+0,997$ & $-0,082$ & \\
FES: Control of Consciousness & $+0,599$ & 0,801 & \\
Average \% variance accounted for & $67,59 \%$ & $32,41 \%$ & Total: $100,00 \%$ \\
Average \% redundancy & $28,44 \%$ & $0,87 \%$ & Total: $29,30 \%$ \\
Canonical correlations & 0,649 & 0,163 & \\
\hline \multirow{2}{*}{. } & & & \\
\hline
\end{tabular}

Note. $\mathrm{n}=168^{*}$ Variate 1 reflected

For the sake of completeness both canonical variables are given. However, only the first variate is statistically significant. From an inspection of Table 5 it is clear that Autonomy has a loading of 0.961 of the $\mathrm{X}$-variate and Internal Control a loading of 0.857 . As far as the Y-variate is concerned Enjoyment has a loading of 0.997 and Control of Consciousness a loading of 0.599 . This clearly indicates a strong relationship between Autonomy and Internal Control on one hand, and both Enjoyment and Control of Consciousness on the other. The associated canonical correlation is 0.649 . Hypothesis 4 is thus supported.

\section{DISCUSSION}

\section{Interpretations}

From the results it is clear that a strong internal locus of control orientation is associated with frequent flow experiences as well as high levels of autonomous behaviour. Causality cannot be proven from the statistical analyses utilised in this study. However, the presence of an internal locus of control, flow and autonomy in a given situation provides a number of insights that were not evident before.

Firstly, with specific reference to the link between flow and autonomy, the body of research relating to the flow construct is consistent in suggesting that individuals experience flow when they are completing a challenging task on their own, without interruption or coaching from a third party (outside of the individual and the task). The link highlighted in this study between autonomy and flow, is in line with these findings (Loubris, et al., 1995). However, to date autonomy has not been clearly highlighted as a condition of flow.

Secondly, with reference to the positive association between an internal locus of control and flow, it can now be suggested that the manipulation of a task in order for the individual to enter into a state of flow, is more complex than understanding the nature of the task and appropriate skills alone. There appears to be a dynamic interaction between the behaviour orientation of the individual (that either results in experience of flow or is caused by flow) and the nature of the task. This challenges research to date that has focused primarily on the nature of the task as being flow-inducing, rather than the nature of the relationship between flow experience and individual factors such as locus of control.

With reference to the sample group in question, the association between internal locus of control, autonomy and flow suggests that students who tend toward a stronger internal locus of control, without close supervision, perform better by experiencing higher levels of flow (optimal experience). This tendency may occur even if such students experience initial obstacles in their performance. Once again it is not clear at this time whether experience of flow results in a stronger internal locus of control orientation or whether internals experience flow more often because they are internals.

Irrespective of the causal relationship it can be suggested that internals would actively seek out strategies to overcome situations of boredom by increasing the task complexity (e.g. selecting a tougher assignment or selecting more courses than required). Similarly they would seek out strategies to overcome anxiety by increasing the level of skill required to complete a task (e.g. by actively seeking tutorials and additional learner support). This behaviour is typically encouraged by university lecturers and study leaders, who know that students perform better if they can work independently at the Higher Education and Training (HET) Institution as well as in their future workplace.

\section{Conclusions}

Rather than presenting a model of the dynamic process taking place between the individual, the task and flow, this study presents an alternative approach to researching the flow construct. This approach focused on researching personal variables in relation to flow rather than the exclusive selection of specific tasks.

\section{Recommendations}

With reference to this study the following recommendations are presented:

1. The factor of autonomy should be added as a condition or characteristic of the flow experience along with the other conditions outlined in the literature study.

2. Future research studies on flow should consider and include personality variables.

3. This study should be incorporated into the development of new conceptual flow/internal locus of control models.

Although a causal relationship could not be established between LOC and flow, the following conceptual model is proposed.

It is recommended that the model depicted in Figure 2 be refined and validated. In doing so universities will be able to develop programmes aimed at bringing out the shift from an external to an internal locus of control. Based on the proposed 


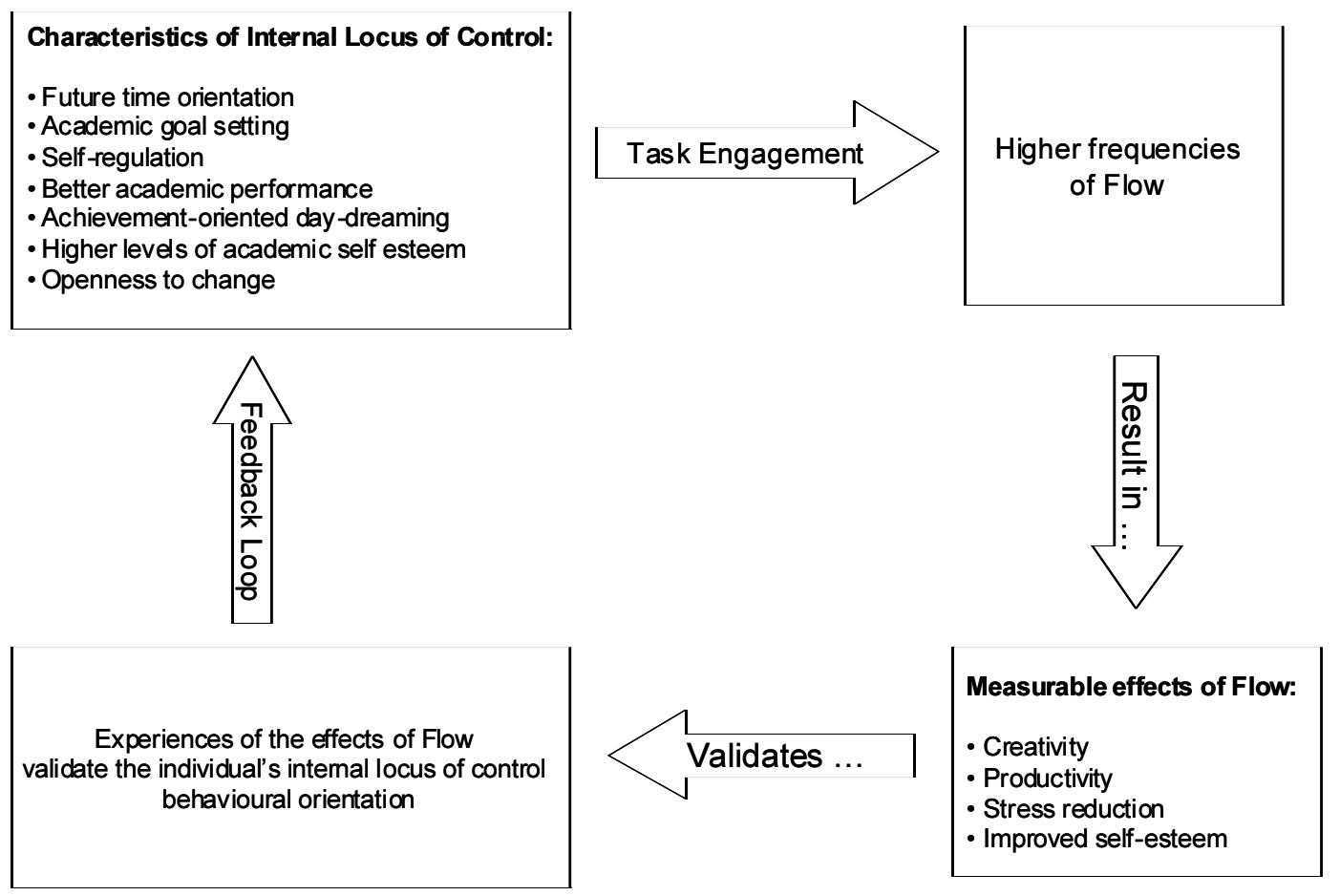

Figure 2: Proposed conceptual model of the relationship between internal locus of control and flow

model, this shift will automatically result in higher levels of flow experience, with all its subsequent benefits (creativity, performance, self-esteem development and stress reduction). Experiences of the benefits of flow could validate behaviours associated with a more internal locus of control.

\section{Limitations}

The limitations of this study lie in the sample that was used. The results only apply to this group of students, who are predominantly Black, female and Sotho speaking. This has resulted in a narrow scope within which the results can be generalised.

Also the size of the sample was too small for a detailed analysis of the measuring instruments. Therefore the validity of both instruments had to be deduced from prior studies conducted, using the instruments.

\section{Suggestions for further research}

The Locus of Control Inventory has predominantly been administered to university students. An opportunity should be sought for the Inventory to be administered to other sample groups, particularly those working in organisations.

With regard to the flow construct, there is a need for further research involving other personality or individual constructs (e.g. Jungian typologies, the Big Five etc.).

The discussion points raised in this paper may also have relevance in the workplace. It is recommended that this study be repeated in the workplace context, particularly in the context of organisational talent development strategies.

\section{REFERENCES}

Alderfer, P.K. (1972). Existence, relatedness, and growth: human needs in organisational settings. New York: Free Press.

Anderson, D.R., Crous, F., \& Schepers, J.M. (1996). Flow and quality of work life in a diverse workforce. Journal of Industrial Psychology, 22 (3), 13-20.

Baars, B.J. (1996). Understanding subjectivity: global workspace theory and the resurrection of the observing self. Journal of
Consciousness Studies; Controversies in Science and Humanities, 3 (3), 211-216.

Blagrove, M., \& Hartnell, S.J. (2000). Lucid dreaming: associations with internal locus of control for cognition and creativity. Personality and Individual Differences, 28 (1), 41-47.

Boyatzis, R.; \& Kolb, D.A. (1995). From learning styles to learning skills: the executive skills profile. Journal of Management Psychology, 10 (5), 3-17.

Brannigan, G.G. \& Hawk, P.A. (1991). Locus of control and daydreaming. Journal of Genetic Psychology, 152 (1), 29.

Butts, D. (1999). Spirituality at work; an overview. Journal of Organizational Change Management, 12 (4), 328-331.

Chalmer, D.J. (1995). Facing up to the problem of consciousness. Journal of Consciousness Studies, 2 (2), 200-219.

Chen, H.; Wigand, R.T.; \& Nilan, M. (2000). Exploring web users' optimal flow experiences. Information Technology \& People, 13 (4). 263-281.

Cohen, P.J. (1991). An exploratory study on peak performance in golf. The Sport Psychologist, 5, 1-14.

Csikszentmihalyi, M. (1990). Flow - The psychology of optimal experience. London: Rider.

Csikszentmihalyi, M. (1992). Flow - The psychology of happiness, New York: Harper Collins.

Csikszentmihalyi, M. (1996). The creative personality. Psychology Today, 29 (4), 5-6.

Csikszentmihalyi, M. (1997). Living Well - The psychology of everyday life. London: Weidenfeld \& Nicolson.

Csikszentmihalyi, M. (2000). The mythic potential of evolution. Zygon, 35 (1), 25-38.

Czubaj, C.A. (1996). Maintaining teacher motivation. Education, 116 (3), 372.

Daniels, K. (2000). Measures of five aspects of affective well being at work. Human Relations, 53 (2), 275.

Das, J.P., Naglieri, J.A., \& Murphy, D.B. (1995). Individual differences in cognitive processes of planning: a personality variable. Psychological Record, 45 (3), 355.

Diamanté, T., \& London, M. (2001). Expansive leadership in the age of digital technology. Journal of Management Development, 21 (6), 404-416.

Dollinger, S.J. (2000). Locus of control and incidental learning: An application to college student success. College Student Journal, 34 (4), 537. 
Editors: Pervin, L.A. \& John, O.P. Handbook of personality (2nd ed.) Chapter 24 (605-628). Attribution in Personality Psychology. Weiner,B. \& Graham,S. 1999: New York: The Guilford Press.

Emiliani, M.L. (1998a). Lean behaviours. Management Decision, 36 (9), 615-631.

Emiliani, M.L. (1998b). Continuous personal improvement. Journal of Workplace Learning, 10 (1) 29-38.

Fink, D., Johnson, M.L., Kennedy, C., \& Porter, C. (2001). Correlation between state anxiety and locus of control. Research Quarterly for Exercise and Sport, 72 (1), 87-90.

Försterling, F. (1988). Attribution theory in clinical psychology. New York: John Wiley \& Sons.

Goulding, C. (2000). The museum environment and the visitor experience. European Journal of Marketing, 34 (3/4), 261-278.

Hair, J.F., Anderson, R.E., Tatham, R.L. \& Black, W.C. (1995). Multivariate data analysis. Englewood Cliffs, N.J: Prentice Hall.

Hanin, Y.L. (2000). Emotions in Sport. Human Kinetics, Champaign: IL.

Harung, H.S. (1996). Peak performance and higher states of consciousness. Journal of Management Psychology, 11 (4), 323.

Harung, H.S. (1997). Enhanced learning and performance through a synergy of subjective modes of change. The Learning Organisation, 4 (5), 193-210.

Heaton, D., Graff, W., \& Alexander. (1996). Peak performance and higher states of consciousness. Journal of Management Psychology, 11 (4), 3-23.

Hefner, P. (2002). Technology and human becoming. Zygon, 37 (3), 655-666.

Herbert, J.T. (1998). The therapeutic effects of participating in an adventure therapy program Rehabilitation. Counselling Bulletin, 41 (3), 201.

Hewstone, M. (1990). Causal attribution; from cognitive processes to collective beliefs. Basil, Blackwell: Massachusetts.

Hong, S., \& Giannakopoulos, E. (1994). The relationship of satisfaction with life to personality characteristics. Journal of Psychology, 128 (5), 547.

Janssen, T., \& Carton, J.S. (1999). The effects of locus of control and task difficulty on procrastination. Journal of Genetic Psychology, 160 (1), 436.

Jaspars, J., Fincham, F. \& Hewstone, M. (Eds.) (1983). Chapter 3. Relevance and Availability. Ajzen, I., \& Fishbein, M. Attribution theory and research: conceptual and social dimensions. Academic Press: London.

Johnson, M.L, Kennedy, C., \& Porter, C. (2001). Correlation between state anxiety and locus of control. Research Quarterly for Exercise and Sport, 72 (L), A-87.

Kalechstein, A.D., \& Nowicki Jr, S. (1997). A meta-analytic examination of the relationship between control expectancies and academic achievement: an 11-year followup to Findley and Cooper. Genetic, Social \& General Psychology Monographs, 123 (1), 29.

Kimweli, D.M.S. (1999). Choice of a major and students appreciation of their major college. Student Journal.

Klein, J. \& Wasserstein-Warnet, M. (2000). Predicitive validity of the locus of control test in selection of school administrators. Journal of Educational Administration, 38 (1), 7-25.

Lasane, T.P., \& Jones, J.M. (1999) Temporal orientation and academic goal setting: the mediating properties of a motivational self. Journal of Social Behaviour and Personality, 14 (1), 31.

Lau, C., \& Woodman, R.W. (1995). Understanding organisational change: a schematic perspective. Academy of Management Journal, 38 (2), 537.

Leith, M. (1996). Organisational change and large group interventions. Career Development International, 1 (4), 19-23.

Lopez, S. L. \& Snyder, C. R. (2003). Positive psychological assessment - $A$ handbook of models and measures. American Psychological Association. Washington, DC.
Loubris, S., Crous, F., \& Schepers, J.M. (1995). Management by objectives in relation to optimal experience in the workplace. Journal of Industrial Psychology, 21 (2), 12-17.

Mamlin, N. (2001). A methodological analysis of research on locus of control and learning disabilities: rethinking a common assumption. Journal of Special Education. (Winter edition).

Maslow, A.H. (1968). Toward a psychology of being. (2nd ed.) Van Nostrand Reinhold.

Maslow, A.H. (1970). Motivation and personality. (2nd ed.) New York: Harper.

McClelland, D.C. (1965). Power: the inner experience. New York: McGraw-Hill.

Mirvis, P.H. (1996). The historical foundations of organisational learning. Journal of Organizational Change Management, 9 (1), 13-31.

Morgan, C. (March 2001). The role of interest in understanding the career choices of female and male college students. Sex Roles: A Journal of Research.

Neck, C.P., Smith, W.A., \& Godwin, J.L. (1997). Thought selfleadership: a self-regulatory approach to diversity management. Journal of Managerial Psychology, 12 (3), 190-203.

Novak, T.P., \& Hoffman, D.L. (1997a). Modelling the structure of flow experience among web users. Unpublished research article Vanderbilt University.

Novak, T.P., \& Hoffman, D.L. (1997b). Measuring the flow experience among web users. Paper presented at the internal research corporation, July 31st, 1997.

Novak, T.P., Hoffman, D.L. \& Duhachek, A. (2003). The influence of goal-directed and experiential activities on online flow experiences. Journal of Consumer Psychology, 13 (1/2) 3-16.

O'Shaughnessy, J. (1997). Temerarious directions for marketing. European Journal of Marketing, 31 (9/10), 677-705.

Pates, J., Karageorghis, C.I., Fryer, R., \& Maynard, I. (2001). Effects of asynchronous music on flow states and shooting performance among netball players. Unpublished report: Sheffield Hallam University, UK.

Pettersen, N. (1987). A conceptual difference between internalexternal locus of control and causal attribution. Psychological Reports, 60, 203-209.

Percival, G., Crous, F., \& Schepers, J.M. (2003). Cognitive potential and job complexity as predictors of flow. South African Journal of Industrial Psychology, 29 (2), 60-71.

Pufal-Struzik, I. (1999). Self actualisation and other personality dimensions as predictors of mental health of intellectually gifted students. Roeper Review, 22 (1), 44-48.

Quinn, B. (2003). Overcoming psychological obstacles to optimal online search. The Electronic Library, 21 (2), 142-153.

Rettie, R. (2001). An exploration of flow during internet use. Internet Research: electronic Networking Applications and Policy, 11 (2). 103-113.

Roberts, J.A., Lapidas, R. S., \& Chonko, L.B. (1998). Sales people and stress: the moderating role of locus of control on work stressors and felt stress. Journal of Personal Selling and Sales Management, 18 (3), 83.

Rosslee, G., Crous, F., \& Schepers, J.M. (1999). The Internal Career of the Type A Personality. Journal of Industrial Psychology, 25 (3), 39-43.

Rotter, J. (1972). Applications of a social learning theory of personality. New York: Holt, Rinehart, \& Winston.

Sashittal, H., \& Jassawalla, A.R. (1998). Why do managers do what they do? Management Decision, 36 (8), 533-542.

Saunders, E. (2000). Assessing human competence: Practical guidelines for the South African manager. Knowledge Resources: Randburg.

Scharmer, C.O. (2001). Self-transcending knowledge: sensing and organising around emerging opportunities. Journal of Knowledge Management, 5 (2), 137-150.

Schepers, J.M., Gropp, L \& Geldenhuys, D.J. (2006). The factor structure, metrical properties and convergent validity of the third edition (1999) of the locus of control inventory. $S A$ Journal of Industrial Psychology, 32 (2), 1-8. 
Sears, B., \& Lawren, B. (1995). Enter the Zone. Regan Books. New York: Harper Collins.

Sheldon, K.M., Elliot, A.J., Kim, K., \& Kasser, T. (2001). What is satisfying about satisfying events? Testing 10 candidate's psychological needs. Journal of Personality and Social Psychology, 80 (2), 325-339.

Shelton, C.K., \& Darling, J.R. (2001). The quantum skills model in management: a new paradigm to enhance effective leadership. Leadership \& Organization Development Journal, 22 (6), 264-273.

Smith, C.L., Sapp, M., Farrel Jr, H. \& Johnson Jr, J.H. (1998). Psycho-educational correlates of achievement for high school seniors at a private school: the relationship among locus of control, self-esteem, academic achievement and academic self esteem. High School Journal, 81 (3), 161.

Smith, N. \& Sivakumar, K. (2002). Flow and internet shopping behaviour: A conceptual model and research propositions. Unpublished article, department of Marketing, Northern Illinois University, 1281 Barsema Hall, DeKalb, Illinois 60115, USA.

Snyder, C. R. \& Lopez, S. J. (2002). Handbook of positive psychology. London: Oxford University Press. 89-101.

Spector, P.E. \& O'Connel, B.J. (1994). The contribution of personality traits, negative affectivity, locus of control and type A to the subsequent reports of job stressors and job strains. Journal of Occupational and Organisational Psychology, 67 (1), 1.

Steyn, R. (1999). The value of using students as participants in educational software development: differentiated outcomes within an open learning environment. Campus-Wide Information Systems, 1 (5), 179-185.

Torbert, W.R. (1991). The power of balance: Transforming self, society and scientific enquiry. Newbury Park, CA: Sage.

Varley, P., \& Crowther, G. (1998). Performance and the service encounter: an exploration of narrative expectations and relationship management in the outdoor leisure market. Marketing Intelligence \& Planning, 16 (5), 311-317.

Weiner, B. \& Graham, S. (1999). Attribution in personality psychology. In l.A. Pervin \& O.P. John (Eds.). Handbook of personality, (2nd ed.). New York: The Guildford Press.

Wolf, F., \& Bandura, A. (1989). Impact on conceptions of ability on self-regulatory mechanisms and complex decisionmaking. Journal of personality and Social Psychology, 56 (3), 407-415.

Yousef, D.A. (2000). The Islamic work ethic as a mediator of the relationship between locus of control, role conflict and role ambiguity - A study in an Islamic country setting. Journal of Managerial Psychology, 15 (4), 283-298. 